\title{
O De Orthographia de Alcuíno de York: Estudo de um Manual do Século VIII
}

\author{
De Orthographia by Alcuin of York: The Study of an 8th Century Medieval \\ orthographic treatise
}

\author{
Everton Grein ${ }^{1}$ \\ Gabrielly Cecília Geisler²
}

\begin{abstract}
${ }^{1}$ Possui Pós doutorado pelo Programa de Pós Graduação em História Social da Universidade de São Paulo (USP, 2017) com pesquisa voltada ao Latim Medieval. Professor Adjunto "A" de História Antiga e História Medieval no Colegiado de História (UNESPAR). Membro do Grupo de Pesquisas "Poder e Sociedade na Península Ibérica Tardo-antiga e Medieval" e membro pesquisador do NeMed (Núcleo de Estudos Mediterrânicos) ambos da UFPR. Possui experiência na área de História Antiga e Medieval, em Filologia Latina. Atuando principalmente nos seguintes temas: História Social, Filologia, Latim Clássico e Medieval, Sistemas de escrita na Antiguidade e Idade Média. E-mail: evgrein@gmail.com.

${ }^{2}$ Graduada em letras Português/Inglês (UNESPAR); Pesquisou pelo PIBIC, o De Orthographia de Alcuíno de York: Estudo de um Manual do Século VIII, pesquisa financiada pelo CNPq. Tem experiência no campo de pesquisa em Latim Medieval e Linguística Histórica. E-mail: gabriellygeisler41@gmail.com.
\end{abstract}

Recebido em 22 de março de 2021; Aceito em 24 de junho de 2021.

DOI: $10.12957 /$ nearco.2021.58587

\section{Resumo}

A pesquisa analisou o De Orthographia de Alcuíno de York, um pequeno manual escrito no século VIII. Para fazer este estudo, analisou-se a biografia de York e o período em que o mesmo viveu, para que assim tivéssemos como base o motivo que o levou a escrever o tratado ortográfico. Essa ideia de comparação entre autor e obra, serviu para analisar quais foram as reformas dentro da De Orthographia e sua contextualização, ou seja, em como se encontrava a língua da época, o latim, e as soluções para a padronização da mesma.

Palavras-chave: Alcuíno de York. De Orthographia. Latim Medieval. Império Carolíngio. Linguística Histórica. Manual Ortográfico Medieval.

\begin{abstract}
The research analysed the De Orthographia by Alcuin of York, a short handbook written in the 8th century. To make this search, the biography of York and the period it lived were analyzed, in order to understand why he wrote the orthographic treatise. This idea of comparison between author and work, were used to analyse what were the reforms within the De Orthographia and its contextualization, that is, in how the language of the time was found, Latin, and the solutions for the standardization of it.
\end{abstract}

Keywords: Alcuin of York. De Orthographia. Medieval Latin. The Carolingian Empire. Historical Linguistics. Medieval Orthographic Treatise. 


\section{Introdução}

O manual ortográfico De Orthographia, foi escrito no século VIII pelo monge Alcuíno de York (730 a 804 d.C.), foi um importante manual não só para seu tempo, a era Carolíngia, como também aos anos que se seguiram. Pois, a partir da eficácia do material como modo de padronização do latim, iniciou-se um grande debate sobre a obra. E assim séculos após a morte de Alcuíno ainda era falado, discutido e comentado sobre a relevância dos apontamentos que estão no De Orthographia, este pequeno manual que possui em torno de 100 páginas.

Deste modo esta pesquisa tem como principal objetivo contribuir como fonte bibliográfica e análise do material do De Orthographia, compreendendo também a importância da figura do monge Alcuíno de York para aquele século (VIII), pois esses possuem extrema relevância para a linguística histórica e para o período Carolíngio, porém tal importância ainda é pouco estudada e debatida. A falta de interesse pelo estudo de Alcuíno de York e o De Orthographia, fica evidente quando analisamos as fontes bibliográficas que são bastante escassas, ressaltando que os poucos pesquisadores que publicam sobre este assunto, e os que costumam publicar, estão em idiomas diferentes do português como, inglês, francês, italiano e até mesmo o latim, ressaltando que não encontramos nenhuma tradução do De Orthographia.

Mas se é pouco estudada, quais foram os motivos que levaram a produção desta pesquisa? Esta pesquisa surgiu através de uma cadeia de informações (que serão citadas abaixo) assim formaram-se as problemáticas, e uma das principais problemáticas foi: Qual é o papel de Alcuíno de York no Renascimento Carolíngio? Em um período de crise cultural, este monge teve um papel fundamental na construção de uma cultura medieval, tal fato ligava-se a outro problema: qual a importância do estudo dos elementos dentro da ortografia de Alcuíno de York para o latim medieval? Pois, existem fontes que o De Orthographia, serviu como base para outros estudos do latim medieval 
e inclusive alguns artifícios que York usou para a padronização da língua ${ }^{148}$ foi um grande sucesso na época, influenciando inclusive as línguas que surgiram após o latim.

Por fim, a pesquisa teve como objetivo geral fazer uma análise sobre a composição, estrutura e abrangência deste manual através dos estudos de gramática histórica. E para poder responder os questionamentos abordados no parágrafo acima, foi feito uma análise do De Orthographia de Alcuíno de York dividindo o trabalho em três partes, que seguindo os objetivos específicos deste estudo, esses trataram em: 1. Demonstrar o papel de Alcuíno de York no contexto das transformações do Renascimento Carolíngio; 2. Analisar a composição de sua obra De Orthographia; 3. Discutir o método empreendido pelo autor em relação ao Latim de seu tempo; 4. Verificar o processo formativo do Latim na Idade Média; e por fim, 5. Inferir sobre a influência e a contribuição de sua obra na Idade Média. Sendo guiada por esses cinco objetivos, foi possível iniciar a pesquisa por quem foi Alcuíno de York e o seu contexto em relação a corte Carolíngia, delimitando e se aprofundando na vida do monge, para assim construir uma introdução para o trabalho e depois elaborar aprofundar-se no manual ortográfico, o De Orthographia.

\section{Metodologia utilizada para analisar o De Orthographia}

Para analisar o De Orthographia foi usado como metodologia, seguir os objetivos descritos na introdução acima, ou seja, seguindo o primeiro objetivo (1. Demonstrar o papel de Alcuíno de York no contexto das transformações do Renascimento Carolíngio), foi elaborada uma pesquisa de quem foi Alcuíno de York e seus principais feitos até a escrita do manual, após isto, foram unidos os objetivos 2 e 3 ( 2. Analisar a composição de sua obra De Orthographia; 3. Discutir o método empreendido pelo autor em relação ao Latim de seu tempo;) e os objetivos 4 e 5 ( 4 . Verificar o processo formativo do Latim na Idade Média; 5. Inferir sobre a influência e a contribuição de sua obra na Idade

\footnotetext{
${ }^{148}$ Quando é dito "padronização da língua", diz respeito às tentativas de deixar a língua homogênea. Isto acontece durante este século pela interferência de vários dialetos de povos conquistados por Carlos Magno, o rei dos Francos, no latim.
} 
Média;). Nos objetivos 2 e 3, foi o momento que a pesquisa mais aprofundou-se no De Orthographia, e para realizar a análise do tratado foi usado a versão de Sandra Bruni (1997, Edizioni Del Galluzzo), nesta edição, a gramática está divida entre sessões, exemplo, <LITTERA A>, que inicia-se no enxerto número [2] e vai até o [47], e segue assim por diante como as outras letras do alfabeto.

Outra característica dessa edição, é que ela possui uma introdução em italiano, porém, o texto do De Orthographia está em latim, ou seja, mantém-se o texto no idioma original escrito por Alcuíno. Por isso, que em alguns momentos deste presente texto, é usado passagens em latim para exemplificar alguns aspectos da gramática, como por exemplo, quando é citado a regra que se aplica em palavras seguidas de A e $C$, [3] Eu acuso, deve ser escrito com dois c's e dois s, e concordo com dois c'c (YORK, 1997, p.3) ${ }^{149}$. Essas citações foram usadas nas explicações de muitas das regras que Alcuíno de York reformulou. E essas reformulações surgem porque não se trata mais de um latim clássico, mas de um latim medieval que foi adaptado pelo autor, para assim o mesmo obter uma padronização da língua ou tentativa de deixar o latim mais homogêneo.

Ao mesmo tempo, que foi usado muitas das citações para explicar regras atribuídas ao idioma por York, como no exemplo dado acima, também foi usado, passagens para comparar o De Orthographia, com outros tratados ortográficos que foram fontes de inspiração para o autor, como por exemplo, Cassiodoro (490-581), Prisciano (viveu entre os séculos V-VI) e Beda, O Venerável (672-735), (PL, 90, col. 123148) esses estudiosos antecessores foram fundamentais para Alcuíno e seu estudo, pois o monge reformulou muito do que esses autores elaboraram, fazendo uma adaptação e inovação em seu tratado, analisando erros e acertos dessas fontes e tentando adaptar para o seu tempo um método que fosse eficaz para a padronização do latim, deste jeito o "ler em voz alta"150, que consistia na pronúncia correta dos fonemas, foi um dos artifícios cruciais para esta reformulação da língua.

\footnotetext{
${ }^{149}$ [3] Accusso per duo cet per duo s scribi debet, accedo per duo c. In: YORK. 1997, p. 03.

${ }^{150}$ O ler em voz alta, é um termo usado por Roger Wright, para explicar como Alcuíno usou do artifício da leitura para a padronização do idioma. Ao longo do texto, haverá um exemplo de como foi utilizado este método.
} 
Para finalizar, através dos objetivos 4 e 5 houve uma análise da importância do tratado para o seu tempo e assim responder às problemáticas da pesquisa relatadas na introdução. Neste momento, foi salientado que uma das características da corte Carolíngia foi o surgimento de vários autores, como Pedro de Pisa, Paulo Diácono, Paulino de Aquiléia... E muitos deles produziram tratados ortográficos, mas nenhum obteve o sucesso que Alcuíno teve, já que o trabalho do monge serviu de base para outros trabalhos posteriores (alguns deles serão citados ao longo do texto), e, graças ao seu trabalho, o latim deste período e dos que se seguiram foi nomeado de latim Medieval ${ }^{151}$.

Foi utilizado como fonte bibliográfica para a análise da ortografia, autores como Ryder Patzuk-Russel (2016), Ernesto Faria (1957), Martin Irvine (2006), Dag Norberg (2007), e Roger Wright, com mais ênfase no artigo Sociophilological Study of Late Latin de Wright (2002), no qual o pesquisador trabalha com o que ele chama de sociofilologia, que é explicado como,

Portanto, para entender todos os aspectos dessas relações, a filologia tradicional, o estudo de textos, é preciso haver uma compreensão mais precisa das circunstâncias históricas e das condições sociais das pessoas que escreveram aqueles textos. Para este fim, recentemente eu inventei o termo 'sociofilologia', no contexto de entender as relações entre latim e romance na alta e baixa Idade Média. (WRIGHT. 2002, p. 133) ${ }^{152}$

Este texto e termo, sociofilologia, foram cruciais para a elaboração desta análise, servindo de embasamento para grande parte do trabalho, Wright é um dos poucos pesquisadores que discute profundamente sobre o De Orthographia, além disso, para entender alguns aspectos como a eufonia ${ }^{153}$ e entre outros problemas que Alcuíno discute em alguns momentos de sua gramática, como por exemplo nesta explicação:

\footnotetext{
${ }^{151} \mathrm{O}$ latim medieval, segundo GOULLET, M. e PARISSE, M., estende-se do século $V$ - XV, este segundo as autoras, passou por tantas mudanças em mil anos quanto passou em oito séculos no que compreende a chamada Antiguidade clássica. In: GOULLET, M. e PARISSE, M. 2019, p. 13

${ }^{152}$ Thus, in order to understand all the aspects of such relationships, traditional philology, the study of texts, needs to be augmented by as precise as possible an understanding of the historical circumstances and social conditions of the people who wrote those texts. To this end I have recently invented the term 'sociophilology', in the context of the relationship between Latin and the Romance languages in the early and central Middle Ages. In: WRIGHT. 2002, p.133
}

${ }^{153}$ Eufonia é um termo da fonética, que diz respeito à pronúncia harmônica de cada fonema. 
[321] Quantus e tantus com n causa a eufonia, vem com efeito de quamtus e tamtus. (YORK. 1997, p. 26) ${ }^{154}$ Isto é, devemos escrever com $N$ porque o resultado da pronúncia [kwantus] é esteticamente preferível do que [kwamtus]. ${ }^{155}$ (WRIGHT, 2002).

Para o levantamento bibliográfico sobre a vida de Alcuíno e do período Carolíngio, foi utilizado autores como, Mary Garrison (1994) e Donald A Bullough (2004), que trabalham mais especificamente a vida de Alcuíno, e Michel Banniard (1989) que discute sobre a Renascença Carolíngia, Priscila Sibim (2013), Terezinha Oliveira (2013), foram usadas como fonte sobre Alcuíno de York e o espelho de príncipe ${ }^{156}$, obra que o monge escreve para um conde, pois este além de ter sido um grande estudioso também foi conselheiro do rei e produziu esses manuais de conduta.

Nessa perspectiva, Alcuíno escreveu sobre as virtudes e os vícios no Livro a respeito das virtudes e dos vícios para o conde Guido. Considerado um "espelho de príncipe" da época, Alcuíno propunha-se a educar um conde com base nos princípios morais defendidos pela fé cristã, perspectiva diferente do ideal de governante em períodos anteriores. (OLIVEIRA, T.; SIBIM, P., 2013, p.20).

Utilizei autores como Maria Rita Sefrian de Souza Peinado (2012) e Mário Alighiero Manacorda (2002), como embasamento sobre o papel de Alcuíno na educação porque este, dedicou-se grande parte de sua carreira como diretor e professor, produzindo o material didático das escolas da corte de Carlos Magno atribuindo como por exemplo, o Trivium e o Quadrivium ${ }^{157}$.

\footnotetext{
${ }^{154}$ [321] quantus er tantus per $n$ euphoniae causa, venit enim a quamtus er tamtus In: YORK. 1997, p. 26.

${ }^{155}$ That is, that we should write it with an $N$ because the resulting pronunciation [kwantus] is aesthetically preferable to [kwamtus]. In: WRIGHT, Roger. Sociophilological Study of Late Latin (Utrecht Studies in Medieval Literacy). Turnhout, Belgium: Brepols, 2002.

${ }^{156} \mathrm{O}$ espelho dos Príncipes ou Specula principum formam um gênero literário bem comum na era carolíngia, apesar de em sua grande, e total, maioria serem escritos por clérigos, no século IX temos exceção com uma mãe aristocrata, casada e leiga, chamada Dhuoda. Esses textos buscavam orientar o nobre, através de exemplos reais, bons ou maus, normas de conduta, postura e seguimento.

${ }^{157} \mathrm{O}$ primeiro é a junção entre a gramática, dialética e retórica, já o segundo, trata-se da união de conhecimentos de aritmética e geometria que são estudos objetivos, com estudos abstratos como a música e a astronomia.
} 


\section{Discussões sobre o Manual}

Através das fontes utilizadas durante a escrita do trabalho, foi possível entender, as estratégias que Alcuíno utilizou para a padronização do latim, respondendo assim uns dos primeiros problemas, que foi citado na introdução do trabalho: "Qual foi o papel de Alcuíno de York no Renascimento Carolíngio?". Ao estudar o período Carolíngio, fica evidente a importância da figura do monge Alcuíno de York, não é nenhuma novidade a sua importância, quando se estuda este período. Porém, historicamente essa presença significativa de Alcuíno, aconteceu por ele ter elaborado vários projetos educacionais como dito anteriormente. O monge foi o braço direito e conselho de Carlos Magno, foi um erudito da época estudando muitas áreas do conhecimento, como matemática, pedagogia e filosofia. A convite de Carlos Magno, ele se tornou um importante professor na corte carolíngia, Eginhardo, o biógrafo do Imperador, chegou a chamá-lo de "o homem mais erudito que existe" (PL, 97, col. 901-902A.). Alcuíno, juntamente com Teodulfo de Orleãns, teve um papel importante na minúscula carolíngia ${ }^{158}$, também fundou inúmeras escolas em muitas das catedrais do império, assim, em 796, foi nomeado como abade do Mosteiro de San Martin de Tours.

Mas a questão que esta pesquisa quer pontuar, não é exatamente sobre os feitos de Alcuíno de York em um sentido geral, a pesquisa limita-se na importância de Alcuíno para o Renascimento Carolíngio em relação ao idioma e a sua gramática De Orthographia, apontando assim quais os fatores que fizeram este manual ortográfico importante para o período.

Sendo assim, no De Orthographia, há várias passagens que Alcuíno faz comentários sobre grafia, há um exemplo acima utilizando a palavra Accuso, Mas além desses comentários gráficos, que são muito comuns na maioria das gramáticas, há também passagens em que é necessário prestar atenção, pois são algumas passagens sobre fonética, mais precisamente focado na prosódia, esses comentários podem ser visto em alguns exemplos dentro da gramática, como em: [38] Accentus quando com

\footnotetext{
${ }^{158}$ Minúscula carolíngia foi uma caligrafia desenvolvida com o objetivo de se tornar a escrita do latim uniformidade, clara e legível, de forma que os documentos, capitulares, pudessem ser facilmente lidos entre as várias regiões.
} 
dois C é levantado a voz em meio a palavra ${ }^{159}$ (YORK, 1997, p.3). Aqui é possível observar que o monge faz uma sugestão de como deve ser articulada a voz quando há a presença de dois cc, na palavra Accentus. Como há essa observação no exemplo [38], há outras passagens que reforçam a eufonia. Há também observações sobre aspiração, que é quando o $\mathrm{H}$ em frente a vogais fica com som de R. Exemplo presente no [180] Pode empregar aspiração diante todas as vogais, no entanto por de trás das consoantes é posto somente em quatro c t p r, como em: habeo hers hiems homo humus Chremes Thraso Philippus Rhodus. Por isso, o H é posto no exterior, pela harmonia, sendo poucas palavras que soem assim, no entanto, quando escrita no interior, a maioria soa como consoante. ${ }^{160}$

Neste momento, Alcuíno no final da sentença cita que propõe que seja pronunciada desta maneira, pelo motivo da harmonia que se embasa na mesma ideia da eufonia. Ou exemplo interessante, é quando dentro da gramática mesmo ele corrige: [88] Coquus com a letra c na primeira sílaba, a segunda deve ser escrita com q: Não falamos quoquere, mas coquere ${ }^{161}$, aqui diferente do exemplo [180], que ele explicou o motivo do $\mathrm{H}$ ser posto no exterior, ele simplesmente corrigiu o modo como deveria ser dito.

Há em outras passagens mais comentários, sobre a eufonia, corrigindo como a palavra deve ser dita, explicando como cada palavra deve ser escrita e o porquê. Basicamente os enxertos citados, dão um pequeno apanhado de como está presente essas correções na gramática. Talvez, por ser ainda nova a ideia de atribuir um som ${ }^{162}$, a cada letra ou fonema, Alcuíno não tenha se estendido mais em suas explicações, dentro do manual. Mas mesmo sendo breve essas observações, elas são de grande

\footnotetext{
${ }^{159}$ [38] Accentus per duo c ubi vox levatur in verbo. In: YORK, 1997, p.3.

${ }^{160}$ [180] Asspiratio ante vocales omnes poni potest, post consonantes autem no entando quattuor tantummodo ponitur c $t$ p $r$, ut habeo hers hiems homo humus Chremes Thraso Philippus Rhodus. $H$ ideo vocalibus extrinsecus ascribitur, ut minus sonet, consonantibus autem intrinsecus, ut plurimum sonet. In: YORK, 1997, p. 17.

${ }^{161}$ [88] Coquus coqui prima syllaba per $c$, secunda per q scribendum est: non nim dicimus quoquere, sed coquere. In:YORK, 1997, p.10.

${ }^{162}$ Este conceito de "atribuir o som a cada letra", será explicada na próxima página.
} 
valor, pois transformam o De Orthographia, em um material autêntico e de extrema relevância para o Renascimento Carolíngio.

Logo, pode-se afirmar que Alcuíno de York foi responsável por grande parte do estudo fonético da língua latina, do qual serviu como base para outros trabalhos que vieram em sucessão ao De Orthographia. Um exemplo de sua influência, foi o Council of Tours (813 d.C.). Neste conselho foram reunidas cinco regiões que naquela época cobriam a extensão territorial do Império, sendo elas, Arles, Chalon, Mainz, Reims, e Tours, este conselho teve como principal objetivo discutir alguns dos progressos promovidos pela comunidade cristã. Um dos tópicos levantados durante essa reunião foi a questão da linguística, na qual escreveram alguns cânones e alguns desses traziam as ideias de Alcuíno, essas ideias foram discutidas por intermédio da comunidade de Tours que trouxe para a discussão o "ler em voz alta" para manter uma pronúncia que fosse clara e de fácil entendimento, construindo assim uma ortografia baseada em sons.

Este trabalho fonético produzido por Alcuíno, teve algumas influências como a epístola litteris colendis ${ }^{163}$, da qual era muito utilizada pelo clero para a melhora da compreensão e da leitura de textos litúrgicos. Houve também inspiração, vindo da litterae de Prisciano que foi inserida por Alcuíno como algo novo no contexto dos carolíngios, Prisciano associou sons particulares para cada letra, e assim Alcuíno utilizouse dizendo, "litterae est pars minima vocis articulatae"164, Cassiodoro (séc. VI d.C.) também influenciou Alcuíno e o mesmo, recebeu o apelido de "O Cassiodoro na corte de Carlos Magno". Cassiodoro escreveu uma De Orthographia ${ }^{165}$, quase ao fim de sua vida, a obra nada mais foi do que um tratado elementar, feita a pedido dos escribas, monges em geral do mosteiro de Monte Cassino, pois estes pediam que o autor produzisse algo mais prático para o trabalho cotidiano do que seus escritos anteriores. Neste tratado de Cassiodoro há várias metodologias e ferramentas pedagógicas, mas

\footnotetext{
${ }^{163} \mathrm{~A}$ epístola, De litteris colendis, MGH Capit. I, no. 29; trans. King (1987), pp. 232-3. Trata-se de uma fonte importante sobre as reformas educacionais carolíngias. A carta também mostra o interesse do imperador Carlos Magno em promover o aprendizado, padronização, e educação em seu Império.

${ }^{164} \mathrm{As}$ letras possuem mínimas partes articuladas pela voz.

${ }^{165}$ Esses tratados todos chamavam-se De Orthographia, pela razão de serem sobre o assunto que iriam tratar, ou seja, a ortografia.
} 
entre elas estão instruções simples de ortografia, "mas entre elas estão as instruções simples de ortografia: observando onde os erros tendem a ocorrer em certas palavras, como quando aggero é escrito com um d e um g, não a geminate" ${ }^{166} \mathrm{~g}$. (PATZUKRUSSELL, 2016, p.13), na De Orthographia do Alcuíno há uma semelhança de composição, se compararmos palavras parecidas agger, Alcuíno escreve como em, [37] Com dois g Agger é escrito quando stratam significa, entretanto se significa campum ubi seminari escreve-se apenas com um g. ${ }^{167}$ (ALCUÍNO DE YORK, 1997, p. 6.) Há alguns autores que dizem, que esse trabalho de Alcuíno foi paralelo a desses autores, porém os efeitos históricos foram muito maiores, já que Alcuíno deixou muito pupilos como Amalário de Metz (780-850) e Pascásio Radberto (785-865), fora a sua influência por causa de Tours, escola administrada pelo monge, esse centro de saber teve grandes referência durante o período do século VIII.

Para a padronização do idioma, o ler em voz alta nos dias de hoje soa um tanto quanto estranho, por isso, para entender melhor esse artifício Roger Wright faz uma analogia com livros infantis, "é o caso de todos os livros para criança, por exemplo. Crianças não sabem como ler sozinhos esses livros, sendo assim eles pedem para que alguém leia em voz alta para que possam entender" 168 (WRIGHT, 2016, p.18). A população iletrada da época, precisava estar ciente do que o documento dizia para então torná-lo legal. Alcuíno, observando isso, construiu uma gramática que possuía recursos para a padronização da pronúncia, essa padronização era o desejo que toda a população medieval do século VIII falasse a mesma língua, sem variações de dialetos.

Para que houvesse essa padronização, York almejou fazer uma pronúncia $\operatorname{artificial}^{169}$ das letras, "essa pronúncia artificial" foi construída pelo monge através da

\footnotetext{
${ }^{166}$ but among them are simple instructions for spelling: noting where errors tend to take place in certain words, such as when aggero is written with a $d$ and a g, not a geminate. In: PATZUK-RUSSELL, 2016, p.13.

${ }^{167}$ Agger per duo g scribendum est quando stratam significat, si autem campum ubi seminari potest per unum g. In: YORK, 1997, p. 6.

${ }^{168}$ as is the case with all books for young children, for exemplo. Not knowing how to read is in itself no bar to understanding something when it is read aloud. In: WRIGHT, 2016, p.18

${ }^{169}$ É chamada de pronúncia artificial, pelo fato de que seria usada para leitura de textos em voz alta, e também por ter sido um modelo criado pelo monge para que a população seguisse, como em um manual de instruções.
} 
utilização de um artifício fonético que consistia na ideia de que, cada letra deveria ser pronunciada conforme Alcuíno estipulou podendo ter algumas variações. É possível elaborar um modelo exemplificando como essa pronúncia artificial era usada, seguindo o alfabeto: $A \rightarrow$ ser lido como [a], as descrições eram feitas de modo que o lado esquerdo deveria conter a letra, e o lado direito como descrito, ser lido em voz alta, ou seja, a representação fonética do som. Em sucessão o: ae $\rightarrow$ [e], seguindo a ordem alfabética, este modelo de pronúncia vai se desenvolvendo, e ao longo dele também há algumas letras que são pronunciadas em circunstâncias específicas, como: i $\rightarrow$ [i] em alguns casos específicos pode ser pronunciada de outra forma, e o $\mathrm{k} \rightarrow$ [k] pronunciado como [k], este quando for encontrado, e assim por diante.

A partir do momento que Alcuíno utilizou-se deste artifício, que foi um sucesso, uma grande revolução aconteceu, muitas pessoas começaram a utilizar os moldes do De Orthographia, para leitura em voz alta. Na literatura, por exemplo, com essa nova imposição de palavras e reformas, os poetas deixaram de rimar e i, o e $u$. Seguindo agora a língua falada, distinguindo as letras através do que estava sendo estipulado, como por exemplo, o e fechado e $e$ aberto.

Todavia, alguns apontamentos que Alcuíno de York fez, não conseguiram mudar alguns dos hábitos dos falante, como por exemplo, quando no De Orthographia, encontra - se:"[178] Hi et his pronomina per unum i scribenda sunt." (ALCUÍNO DE YORK, 1997, p.17) ou seja, hi e his, devem ser apenas usados com i, segundo Norberg (2007), os maus hábitos continuaram, as pessoas mantiveram a escrita de Hii e hiis, "se bem que no século XIII um outro gramático, Alexandre de Villedieu (Villedieu = Cidade de Deus), que recomenda a pronúncia com um só $i$, se vê obrigado a admitir a ortografia hii e hiis"' (NORBERG, 2007, p.65). Se ele se sentiu obrigado a introduzir isso na ortografia, lembrando que, provavelmente o que Alcuíno propôs fazia algum sentido, apesar das pessoas não usarem como foi apontado por Norberg.

Sendo assim, para que não houvesse mais enganos, o monge analisou quais foram as maiores dificuldades da época e trouxe como solução dentro da linguagem o que era mais usado, sendo, a fala, "o ler em voz alta", foi a maior ferramenta de comunicação utilizada nessa nova língua artificial, e é importante comentar que possui 
esse nome: Linguagem artificial, porque o que Alcuíno de York propôs não era uma linguagem que voltava as normas antigas, ou seja, não era latim clássico, mas sim uma nova língua, que Ernesto Faria (1957) diz como "um latim clássico mal falado"(FARIA,1957, p.126), para um latim que se moldou de acordo com as necessidades que o autor acreditou que eram apropriadas para os falantes de latim daquele período (VIII). Além disso, o sistema adotado por Alcuíno serviu como empréstimo linguístico para outras línguas que derivaram do latim, como é o caso principalmente do francês.

$\mathrm{Na}$ dinastia Merovíngia que foi a antecessora da Carolíngia, era difícil escolher, por exemplo, entre as letras $e$ e $i$, $o$ e $u$, porque, em sílaba acentuada, $i$ breve se confundia com $e$ fechado e $u$ breve se confundia com $o$ fechado na pronúncia cotidiana (NORBERG, 2007, p.64).

Algo que Alcuíno abominava eram essas confusões que poderiam atrapalhar o leitor, o maior exemplo são letras mudas, como $\mathrm{P}$ e $\mathrm{D}$ no português, pois causam dúvidas sobre a pronúncia, como em advogado, em que a variação mais comum para: Adevogado. Deste modo, com as reformas que foram propostas durante o Império Carolíngio, acabou-se essa confusão, pois, foram retiradas muitas dessas letras que causaram confusões, e quando houve essa migração dentro da língua é possível encontrar vestígios dessas transformações dentro das línguas vulgares, como o antigo francês e o português. Norberg (2007), diz que,

Os vocábulos eruditos titulus e dignus foram pronunciados com um $i$, diluvium e studium com um $u$, e complementa dizendo, sendo no francês antigo, titele, digne e diluvie, estudie, e do português título, digno e dilúvio, estúdio tomados do latim depois da reforma (NORBERG, 2007, p. 64).

Com este breve resgate fonético feito acima utilizando Ernesto Faria (1957) e Norberg (2007), e com a análise elaborada ao longo de toda a pesquisa, a importância do estudo dos elementos da ortografia desde o período Medieval através da obra de Alcuíno de York (um dos problemas que também foi apresentado acima), fica evidente que o De Orthographia teve um papel fundamental para o modo como o latim medieval, moldou-se no século VIII, tentando uma padronização através da correspondência do latim aos seus falantes. Mesmo a língua se perdendo ao longo dos anos, a padronização 
que ele aplicou influenciou uma nova perspectiva de latim medieval, após o século VIII, sendo ele o principal responsável pela reconstrução de alguns fonemas da língua, não através de moldes clássicos, mas através do que já era falado entre os falantes de latim daquela época, sendo assim, sua gramática conseguiu sistematizar essas variações para organizar a língua falada daquele século, fazendo o De Orthographia uma reconstituição, como maneira de salvar o idioma.

Por conseguinte, a importância de estudar figuras como Alcuíno de York atualmente é pela valorização dessa figura quanto ao latim da época medieval, pois, tratando-se da fonética Alcuíno de York teve um papel revolucionário. Em a fonética histórica do latim de Ernesto Faria, cita Alcuíno como um dos mais eruditos do período, “em seu tratado ortográfico discute Alcuíno numerosas palavras latinas... e seu emprego em conexão com a pronúncia do Latim" (FARIA, 1957, p. 126). E continua explicando que, o monge faz um trabalho fonético, do qual consiste em pegar os hábitos adquiridos dentro da língua, pelos falantes e logo após rompe esses hábitos entre a língua culta e vulgar trabalhando na reconstrução do idioma. Ou seja, Alcuíno fez uma análise de como as pessoas estavam falando, e como estava caminhando o idioma. Ele, não fez exatamente um resgate da linguagem clássica trazendo talvez algo mais arcaico, mas sim, ele foi extremamente moderno em olhar de fora a "matéria que iria trabalhar" e trazer no texto novas argumentações sobre o idioma, como, tirar aquilo que atrapalhava os falantes trazendo a facilidade e clareza para que todos conseguissem entender e comunicar-se de forma clara. Até mesmo, no texto de Faria (1957), diz que, Alcuíno ignorava a verdadeira pronúncia do latim clássico. E ainda o autor complementa tal afirmação seguindo com,"O latim era pronunciado de uma forma que não era popular nem clássica" (FARIA, 1957, p. 126). Logo, podemos afirmar inclusive que essa nova estrutura transformou a fonética do latim, além do rompimento com a língua clássica. Deste modo, fica evidente os motivos de classificar esse período, como o restaurador do latim medieval. 


\section{Conclusão}

Para a finalização do processo de pesquisa, reforça-se sobre os poucos autores que trabalham Alcuíno de York e a De Orthographia, citando breves trechos e fragmentos sobre o que foi a ortografia de maneira concisa, deste modo a análise aprofundada, contribui para o acervo bibliográfico do manual, pois, ao estudar a obra, foi encontrado resultados que apenas fragmentos e uma rápida explanação não conseguiram abranger.

O apontamento mais importante encontrado na pesquisa foi o viés da fonética que Alcuíno utilizou para elaborar o material, já que o mesmo utilizou, as letras com seus mínimos sons, dentro da fonética: os fonemas. Coloca-se esse ponto como crucial para tentar restabelecer uma língua homogênea. Quando Alcuíno de York descreveu esses fonemas, ele deixou de ignorar a língua falada, diferenciando-se da maioria dos autores da época, pois, se analisarmos historicamente o latim escrito e o latim falado, o primeiro manteve-se inalterado e o segundo teve várias variações, automaticamente o De orthographia, é uma fonte histórica muito rica de como se encontrava o latim na idade medieval.

Portanto, é perceptível a importância do autor para seu período, já que muitos estudiosos chamam a época Carolíngia como, renascença Carolíngia, pois essa foi responsável por uma transformação cultural e linguística. Já que, o De Orthographia foi usado como referência para outros trabalhos posteriores a Alcuíno, comprovando, a quão promissora é essa área e quanto ainda se tem a estudar. Pois, quando foi citado, acima, Alexandre de Villa Dei, este teve seus dois tratados de gramática medievais publicados pela última vez em 1504-1509, respectivamente, e neste período ele ainda estava usando como referência Alcuíno de York tendo que inclusive adaptar a sua análise ao que o monge propôs. Percebam que o manual ortográfico do monge foi produzido no séc. VIII, desta maneira comprova o quanto de material sobre o latim medieval precisa ainda ser estudado.

Entendendo a metodologia usada por Alcuíno para a padronização do idioma, é comprovada a importância de Alcuíno em diversos aspectos do idioma, mudando 
inclusive como dito acima, a maneira como os poetas rimaram as palavras, e até trazendo um trabalho linguístico muito antes de se ter base do que é a linguística, a gramática de York antes de apontar erros, foi uma proposta para manter a língua viva e recuperá-la não através de normas técnicas que dificilmente funcionaria, mas dentro de um trabalho minucioso e reconhecendo os fonemas dentro da língua, muito antes de se ter base sobre o que eram fonemas, isso trouxe facilidade para impedir os erros básicos que as pessoas cometiam. Um exemplo desses erros básicos, é quando na análise da $D e$ Orthographia, é comentado fenômenos como a da eufonia, quando Alcuíno de York afirma ser contra as letras mudas, ou qualquer variação que pudesse causar dúvidas de pronúncia, pois são essas dificuldades que levam os falantes ao erro. Para que não houvesse mais esses enganos de pronúncia, o monge analisou quais foram as maiores dificuldades da época e trouxe como solução, esta linguagem artificial.

Portanto, é indiscutível a importância do monge para o latim medieval, pois ele foi responsável por uma nova perspectiva de estudo da língua na Idade Média, e inclusive pela tentativa da construção de uma fonética do latim medieval que foi explanada e argumentada dentro desta análise do De Orthographia, percebendo assim a solução que Alcuíno utilizou "para virar o jogo" enquanto a padronização do latim do séc VIII.

\section{Referências Bibliográficas}

ALCUINUS. De Orthographia. In: MIGNE, J. P. Patrologiae Latinae, Vol. Cl (101). 901920A. Paris: 1863.

ALCUÍNO DE YORK. De orthographia. Edição de BRUNNI, S. Firenze: SISMEL, 1997.

BANNIARD, Michel. Génese Cultural da Europa: Século V - VIII. Lisboa: Terramar, 1989.

BULLOUGH, Donald A.. Alcuin: Achievement and Reputation:: Being Part of the Ford Lectures Delivered in Oxford in Hilary Term 1980. Países Baixos: Brill, 2004.

EGINHARDUS. Vita caroli magni. In: MIGNE, J. P. Patrologiae Latinae, Vol. XCVII (97). 901-920A. Paris: 1863.

FARIA, Ernesto. Fonética Histórica do Latim. Rio de Janeiro: Livraria Acadêmica, 1957. 
GARRISON, Mary. The Emergence of Carolingian Latin Literature and the Court of Charlemagne. In: MCKITTERICK, Rosamond. Carolingian Culture: Emulation and Innovation. Cambridge: Cambridge University Press, p. 111-140, 1994.

GOULLET, Monique; PARISSE, Michel. Aprenda o Latim Medieval: manual para um grande começo. Campinas: Editora Unicamp, 2019.

IRVINE, Martin. The Making of Textual Culture: 'Grammatica' and Literary Theory 3501100. Inglaterra: Cambridge Studies In Medieval Literature, 2006.

MANACORDA, Mário Alighiero. História da Educação: Da antiguidade aos nossos dias. São Paulo: Cortez, 2002.

NORBERG, Dag. Manual prático de Latim Medieval: (I - Breve história do Latim Medieval). Rio de Janeiro: Cifefil, 2007.

OLIVEIRA, Terezinha; SIBIM, Priscila. Mestre Alcuíno e a formação da liderança carolíngia: uma análise de "Espelho de Príncipe". Imagens da Educação, Maringá, v. 3, n. 1, p.19-29, 14 mar. 2013. Universidade Estadual de Maringá. Disponível em: <http://dx.doi.org/10.4025/imagenseduc.v3i1.19558>. Acesso em: 21/03/2021.

PATZUK-RUSSELL, Ryder. Ideologies and Rhetoric of Language in the Icelandic Grammatical Treatises. Quaestio Insularis, Cambridge, v. 16, p.60-89, 2016.

PEINADO, Maria Rita Sefrian de Souza. O ensino do Trivium e do Quadrivium, a linguagem e a história na proposta de educação agostiniana. Imagens da Educação, [s.l.], v. 2, n. 1, p.1-10, 8 fev. 2012. Universidade Estadual de Maringa. Disponível em: <http://dx.doi.org/10.4025/imagenseduc.v2i1.15808>. Acesso em:21/03/2021.

VENERABILIS BEDA. De Orthographia. In: MIGNE, J. P. Patrologiae Latinae, Vol. XC (90). 9-62. Paris: 1862.

WRIGHT, Roger. Latin and Romance in the medieval period. The Oxford Guide To The Romance Languages, [s.I.], p.14-23, 30 jun. 2016. Oxford University Press. Disponível em: <http://dx.doi.org/10.1093/acprof:oso/9780199677108.003.0002>. Acesso em: $21 / 03 / 2021$.

WRIGHT, Roger. Sociophilological Study of Late Latin: (Utrecht Studies in Medieval Literacy). Turnhout, Belgium: Brepols, 2002. 